\section{idenotiene}

Jurnal Kajian Manajemen Dakwah

\title{
Muallaf Center BKMR An-Nur Provinsi Riau: Layanan Pendampingan dan Pembinaan Kepada Muallaf
}

\author{
Artis $^{1}$ \\ ${ }^{1}$ Universitas Islam Negeri Sultan Syarif Kasim Riau \\ Email: artis@uin-suska.ac.id
}

\begin{abstract}
This article deals with the role of Muallaf (Muslim Converts) Center of the BKMR An-Nur Riau to provide service and guidance for Muslim converts. This article is beneficial because from 2016 to 2018 the number of Muslim converts have increased significantly. The main question is how the role of Muallaf (Muslim Converts) Center of the BKMR An-Nur Riau to provide service and guidance for Muslim converts is. Using interview, observation and documentation, the Muallaf (Muslim Converts) Center of the BKMR An-Nur Riau provides service and guidance for Muslim converts as follows; The first is its role as facilitator in which it gives motivation, support and guidance. The second is its role as administrator in which it records the prospective Muslim converts, provides certificate, and guides the conversion process. The third is its role as counselor. The fourth is its role as providing guidance in the form of enforcing aqidah (theology), Islamic law, Islamic jurisprudence, Qur'an, and general discussion.
\end{abstract}

Keywords: Role, Muallaf Center, Service, Guidance

\begin{abstract}
Abstrak: Tulisan ini membahas tentang peran Muallaf Center BKMR An-Nur Provinsi Riau dalam memberikan layanan pembinaan kepada Muallaf. Tulisan ini penting dilakukan karena sejak tahun 2016 hingga 2018 jumlah Muallaf di Muallaf Center BKMR An-Nur terus meningkat. Pertanyaan utama yang akan dijawab dalam tulisan ini adalah bagaimana Muallaf Center BKMR An-Nur Provinsi Riau memberikan layanan pembinaan kepada Muallaf. Melalui wawancara, observasi dan dokumentasi yang saya peroleh, Muallaf Center BKMR An-Nur memberikan beberapa layanan pembinaan kepada Muallaf di antaranya: Pertama, layanan fasilitator seperti memberikan motivasi, dukungan, dan bimbingan. Kedua, layanan administrasi seperti mendata calon Muallaf, memberikan surat ikrar, dan membimbing prosesi ikrar syahadat. Ketiga, layanan konseling. Keempat, layanan motivasi dan terakhir melakukan layanan pembinaan berupa penguatan akidah, syariah, fikih, belajar iqra, dan diskusi umum.
\end{abstract}

Kata Kunci: Peran, Muallaf Center, layanan, Pembinaan

\section{Pendahuluan}

Tulisan ini membahas tentang peran Muallaf Center Badan Kemakmuran Masjid Raya (BKMR) An-Nur Provinsi Riau dalam memberikan layanan pendampingan dan pembinaan kepada Muallaf. Tulisan ini penting dikaji, karena jumlah Muallaf di Muallaf Center BKMR An-Nur terus meningkat dari tahun 2016 sampai 2018. Melalui data yang saya peroleh, pada tahun 2016 jumlah Muallaf mencapai 88 orang yang terdiri dari 36 orang berjenis kelamin laki-laki dan 52 orang perempuan. Jumlah ini baik yang berasal dari dalam maupun luar kota Pekanbaru. Kemudian pada tahun 2017, jumlah Muallaf bertambah hingga mencapai 101 orang yang terdiri dari 41 orang laki-laki dan 60 orang perempuan. Hingga data terakhir yang 
saya dapatkan pada tahun 2018, jumlah Muallaf di Muallaf Center BKMR An-Nur mencapai 112 orang yang terdiri dari 56 orang laki-laki dan 56 orang perempuan (Dokumentasi Muallaf Center BKMR An-Nur Provinsi Riau).

Dengan jumlah Muallaf yang semakin bertambah tersebut, tentu saja menuntut peran Muallaf Center yang lebih serius dalam memberikan layanan pembinaan terhadap mereka. Tujuannya adalah untuk memfasilitasi, meyakinkan dan bahkan mempertahankan pilihan (keimanan) mereka untuk memeluk agama Islam. Oleh karena itu, penelitian yang berfokus untuk melihat bagaimana peran institusi keagamaan non-pemerintah dalam memberikan layanan pendampingan dan pembinaan kepada Muallaf seperti yang penulis lakukan menjadi signifikan untuk dilakukan. Tulisan ini berpendapat bahwa peran institusi keagamaan nonpemerintah sangat penting dalam memberikan layanan pembinaan kepada Muallaf. Mereka yang baru masuk ke dalam agama Islam (Muallaf), biasanya masih berada dalam situasi kebimbangan dan kebingungan terhadap pilihan dan praktik ibadah keyakinannya yang baru, sehingga membutuhkan pendampingan dan penguatan spiritual dari berbagai pihak, termasuk lembaga atau institusi keagamaan non-pemerintah seperti Muallaf Center BKMR An-Nur di Provinsi Riau.

Studi tentang Muallaf telah banyak dilakukan oleh sejumlah sarjana. Semisal, studi yang dilakukan oleh Titian Hakiki dan Rudi Cahyono (2015:20-28), mereka membahas tentang bagaimana Muallaf berkomitmen memahami, menjalankan, dan mempertahankan keyakinan beragamanya. Berbeda dengan Hakiki dan Cahyono, studi yang dilakukan oleh Masduki dkk (2019: 425-450) mengkaji tentang pemberdayaan terhadap Muslim Muallaf melalui home industri kerupuk ikan lomek. Hasil studinya menunjukkan bahwa penguatan akidah Muslim Muallaf dapat dikuatkan melalui perbaikan dan penguatan dari sisi ekonomi mereka. Kemudian studi yang dilakukan oleh Ramlah Hakim (2013: 85-96) menjelaskan tentang bagaimana pola pembinaan Muallaf yang dilakukan oleh pemerintah dan lembaga keagamaan seperti Nahdatul Ulama (NU), Muhammadiyah, DDI, Wahdah, Al-Irsyad,dan LDII. Studi yang dilakukan Hakim tidak menyentuh pada pembinaan Muallaf berbasis masjid. Sedangkan penelitian saya akan mengkaji tentang layanan pendampingan dan pembinaan yang dilakukan oleh lembaga keagamaan berbasis masjid yaitu BKMR An-Nur Provinsi Riau.

Berbeda dengan studi-studi sebelumnya dan latar belakang yang telah disampaikan di atas, tulisan ini mengambil focus yang berbeda yaitu melihat tentang bagaimana peran Muallaf Center BKMR An-Nur Provinsi Riau dalam memberikan layanan kepada Muallaf. Adapun tujuan penelitian ini adalah untuk mengetahui bagaimana Eksistensi Muallaf Center BKMR An-Nur Provinsi Riau Dalam memberikan layanan terhadap Muallaf.

\section{Metode}

Jenis penelitian yang digunakan adalah deskriptif kualitatif yaitu data diperoleh dan disajikan dalam bentuk kata/kalimat, gambar, penjabaran, dan pendeskripsian secara jelas dan detail (Pasolong, 2013: 69). Sumber data yang digunakan berupa data primer yaitu data yang diperoleh dari hasil wawancara dengan narasumber dan observasi yang dilakukan secara berkala. Sedangkan data sekunder yaitu data yang diperoleh dari lokasi penelitian yang 
berkaitan dengan dokumentasi seperti laporan, buku, foto dan semua yang berhubungan dengan masalah penelitian yang sedang diteliti. Informan sebanyak empat orang terdiri dari Ketua, Wakil, Sekretaris, dan Bendahara Muallaf Center BKMR An-Nur Provinsi Riau. Untuk mendapatkan keabsahan data maka digunakanlah teori Triangulasi. Triangulasi ini dilakukan untuk melakukan pengecekan terhadap penggunaan metode pengumpulan data, apakah informasi yang didapat dengan interview sama dengan observasi. Apabila terdapat perbedaan, maka akan dijelaskan alasan perbedaan itu. Tujuannya untuk mencari kesamaan dengan metode yang berbeda (Bungin, 2003: 257).

\section{Hasil dan Pembahasan}

Berdasarkan hasil wawancara, observasi dan dokumentasi yang saya lakukan bahwa peran Muallaf Center BKMR An-Nur Provinsi Riau dalam memberikan layanan pendampingan dan pembinaan kepada Muallaf meliputi 5 aspek yaitu:

\section{Muallaf Center BKMR An-Nur Sebagai Fasilitator}

Fasilitator adalah sekelompok orang yang mendampingi, memberikan semangat, pengetahuan, bantuan, saran kepada suatu kelompok untuk memecahkan masalah sehingga kelompok yang difasilitasi dapat lebih maju. Filosofi dari fasilitator adalah adanya suatu kelompok yang memiliki tujuan, rencana, gagasan, program, sarana dalam melaksanakan kegiatan dalam memecahkan masalah yang dihadapi secara bersama-sama (Coulson, 1996: 54).

Ketika calon Muslim datang dan mendaftarkan diri untuk memeluk agama Islam, Muallaf Center BKMR An-Nur Provinsi Riau akan memfasiltasi bagaimana proses sebelum prosesi pensyahadatan dilaksanakan dan setelah menjadi seorang Muallaf. Kemudian Muallaf Center BKMR An-Nur Provinsi Riau akan memberikan buku-buku tentang ajaran Islam kepada para Mullaf. Muallaf Center BKMR An-Nur Provinsi Riau akan menjadi fasilitator terhadap calon Muslim dan Muallaf baik itu dari segi dukungan, motivasi, dan bimbingan sebab calon Muslim sangat membutuhkan informasi terkait tata cara dan syarat-syarat apa saja yang diperlukan untuk melaksanakan prosesi pensyahadatan. Ketika calon Muslim sudah melakukan ikrar syahadat dan sudah menjadi Muallaf, mereka harus dibimbing agar mereka tidak bingung ketika sudah memeluk agama Islam dan ketika para Muallaf sudah memeluk agama Islam dan sudah berbeda keyakinan dan kebiasan dengan agama sebelumnya, para Muallaf harus dibimbing sehingga keyakinannya terhadap Islam semakin tinggi. Oleh karena itu, Muallaf Center BKMR An-Nur Provinsi Riau akan memfasilitasi para Muallaf baik itu dari segi bimbingan dalam bentuk pelaksanaan ibadah dan belajar Al-Quran agar mereka tetap istiqomah dan imannya selalu terjaga.

Fasilitas yang disediakan oleh Muallaf Center BKMR An-Nur Provinsi Riau berupa AlQuran dan terjemahan, buku iqro, dan buku tuntunan sholat untuk para Muallaf. Selain itu, bagi Muallaf wanita akan diberikan mukenah, dan laki laki akan diberikan kain sarung. Muallaf Center BKMR An-Nur Provinsi Riau tidak hanya memberikan fasilitas dalam segi barang dan tempat belajar, tetapi juga memberikan fasilitas berupa dukungan motivasi dan menerima keluh kesah para Muallaf dalam konteks mempelajari ilmu agama Islam dan ketika Muallaf memiliki masalah dalam mempelajari ilmu agama Islam, Muallaf Center BKMR An- 
Nur Provinsi Riau siap untuk menjadi fasilitator dan memberikan solusi terkait hal itu. Kemudian para Muallaf yang ingin melakukan belajar tambahan agar lebih cepat memahami ilmu agama Islam, Muallaf Center BKMR An-Nur akan memfasilitasi, baik itu materi yang akan diberikan, waktu, dan tempat belajar untuk para Muallaf. Muallaf Center BKMR AnNur Provinsi Riau tidak memberikan fasilitas berupa tempat tinggal untuk Muallaf yang bertransmigasi dari suatu tempat ke tempat lainnya. Lembaga ini hanya memberikan fasilitas dalam segi kebutuhan spiritual seperti mempelajari ilmu agama Islam, dan dalam segi motivasi dan moral.

\section{Muallaf Center BKMR An-Nur Sebagai Administrator}

Peran Adminstrator bagi calon Muslim dan para Muallaf sangat penting, karena pelayanan berupa adminstrasi sangat berpengaruh untuk proses calon Muslim menjadi seorang Muallaf. Kemudian administrasi sangat berperan penting bagi para Muallaf sebagai data base agar para Muallaf menjadi seorang Muslim yang legal dan bersertifikat. Langkah yang dilakukan ketika calon Muslim sudah mengisi formulir, maka Muallaf Center BKMR An-Nur Provinsi Riau akan memindahkan data-data calon Muslim ke dalam surat ikrar. Surat ikrar tersebut akan disiapkan pada hari jumat ketika calon Muslim akan melakukan prosesi ikrar syahadat. Calon Muslim yang akan melakukan ikrar syahadat akan dibimbing oleh seorang tokoh agama atau penghulu. Namun, sebelum prosesi itu dilaksanakan, calon Muslim harus menandatangani sejumlah berkas disertai tanda tangan penuntun/pembimbing yang akan mensyahadatkan, dan tanda tangan para saksi di dalam surat ikrar. Proses berikutnya adalah pembuatan sertifikat bagi para Muallaf.

Kemudian para Muallaf menjalani atau mengikuti pembinaan yang dilaksanakan 4 kali dalam satu bulan setiap hari Ahad (Minggu). Para Muallaf yang sudah memenuhi standar lulus dari pembinaan yang dilakukan oleh Muallaf Center BKMR An-Nur Provinsi Riau, maka sertifikat akan diberikan kepada para Muallaf. Sampai di sini tampak jelas peran administrator Muallaf Center BKMR An-Nur. Administrator sebagaimana dijelaskan oleh Hary King dan Sugyono adalah seseorang atau orang-orang yang bertugas untuk mengurusi hal-hal administrasi (Hary King dan Sugiono, 12).

Fungsi administrasi Muallaf Center BKMR An-Nur Provinsi Riau terbagi menjadi dua: Pertama, fungsi administrasi bagi calon Muallaf guna melengkapi data-data calon Muallaf untuk melakukan prosesi pensyahadatan. Kedua, untuk para Muallaf, adminstrasi berfungsi sebagai data base para Muallaf di Muallaf Center BKMR An-Nur Provinsi Riau. Kemudian hal ini juga berguna untuk proses pembuatan sertifikat yang akan diberikan kepada para Muallaf. Kemudian apabila ada lembaga pendidikan ataupun lembaga-lembaga lain yang memerlukan data para Muallaf, maka Muallaf Center BKMR An-Nur Provinsi Riau sudah mempunyai data base para Muallaf.

\section{Muallaf Center BKMR An-Nur Sebagai Konselor}

Konselor merupakan pendidik atau tenaga profesional yang bertugas merencanakan dan menyelenggarakan proses pembelajaran, menilai hasil pembelajaran, melakukan bimbingan dan pelatihan. Adapun arah pelaksanaan pembelajaran dan penilaian hasil pembelajaran yang 
dimaksud adalah melaksanakan pelayanan bimbingan dan konseling dalam berbagai jenis layanan dan kegiatan. Tugas utama bimbingan adalah memperhatikan individu dan membantu menemukan jalan yang tepat sesuai dengan pandangan masyarakat untuk mengekspresikan keunikan dirinya. Selain itu, konselor adalah guru pembimbing yang membantu siswa untuk menjalani bimbingan tersebut (Gunawan, 1992, 20).

Ketika calon Muallaf datang ke Muallaf Center BKMR An-Nur Provinsi Riau untuk mendaftarkan diri menjadi seorang Muallaf, maka sekretaris Muallaf Center BKMR An-Nur Provinsi Riau akan memberikan konseling tentang Islam kepada calon Muallaf di awal pendaftaran. Pemberian bimbingan konseling tersebut bertujuan agar calon Muallaf tahu apa yang harus dilakukan dan yang tidak boleh dilakukan setelah menjadi Muslim. Setelah calon Muallaf sudah berikrar dan menjadi Muslim, bimbingan konseling tentang Islam akan diberikan di sela-sela waktu pembinaan yang sudah ditentukan. Proses bimbingan konseling yang diberikan Muallaf Center BKMR An-Nur Provinsi Riau berbeda-beda antara calon Muallaf dengan para Muallaf lain. Proses bimbingan konseling yang berdasarkan janji, tidak dilaksanakan bersamaan dengan para Muallaf yang lain, melainkan bimbingan konseling di berikan secara individu dan eksklusif, karena setiap Muallaf memiliki problem dan privasi yang berbeda-beda dalam memahami tentang ajaran agama Islam.

Narasumber yang memberikan konseling tentang nilai Islam kepada calon Muallaf antara lain: Afra Khanza selaku sekretaris Muallaf Center BKMR An-Nur Provinsi Riau, dan Ustaz M. Hanafi, S.Pd.I selaku ustaz pembina mengenai materi akidah, syari'ah dan fikih pada tahun 2016-2017. Pada perjalanannya, karena keterbatasan SDM pada tahun 2018-2019 tidak ada ustaz yang memberikan bimbingan konseling secara khusus tentang nilai Islam kepada calon Muallaf. Untuk mengatasi hal ini, Muallaf Center BKMR An-Nur Provinsi Riau berupaya melakukan kerjasama dengan berbagai pihak agar program ini tetap berjalan sesuai harapan bersama.

\section{Muallaf Center BKMR An-Nur Sebagai Motivator}

Motivator adalah orang yang memiliki profesi atau pencaharian dari memberikan motivasi kepada orang lain. Pemberian motivasi ini biasanya melalui pelatihan (training), namun bisa juga melalui mentoring, coaching atau counselling. Istilah motivator juga dapat ditujukan untuk menyebut orang yang memberikan rangsangan kepada orang lain untuk melakukan sesuatu, pendorong atau penggerak (Sudarmo, 1990: 30).

Calon Muallaf yang ingin memeluk agama Islam mereka memiliki latar belakang yang berbeda-beda. Ada calon Muslim yang berasal dari keluarga yang tidak terlalu fanatik dengan agama dan tidak keberatan jika calon Muallaf tersebut akan berbeda agama dengan keluarganya ketika sudah menjadi seorang Muallaf. Namun, ada juga calon Muallaf yang berasal dari keluarga yang sangat fanatik dengan agamanya dan tidak menyukai jika calon Muallaf tersebut memeluk agama Islam danberbeda keyakinan dengan keluarganya. Bagi calon Muslim yang berasal dari latar belakang keluarga yang sangat fanatik dengan agamanya, hal tersebut akan membuat calon Muallaf merasa goncang jiwanya dalam menghadapi hal tersebut seperti merasa dikucilkan dari keluarganya. Oleh karena itu, keberadaan Muallaf Center BKMR An-Nur Provinsi Riau sangat penting sebagai motivator 
bagi calon Muallaf agar bisa memberi penanganan dalam hal tersebut, terutama dalam memberikan motivasi dan dukungan untuk menguatkan mental dan niat calon Muallaf agar tetap terjaga keistiqomahannya. Pelayanan dalam bentuk motivasi yang diberikan oleh Muallaf Center BKMR An-Nur Provinsi Riau baik secara langsung maupun melalui media seperti handphone. Bagi para Muallaf yang jauh atau berhalangan dan tidak bisa datang maka para Muallaf bisa menyampaikan problemnya melalui media sosial seperti komunikasi langsung melalui handpone atau Whatsapp (WA). Jika hal tersebut tidak selesai melalui media maka diharapkan para Muallaf untuk datang ke kantor Muallaf Center BKMR An-Nur Provinsi Riau agar diberikan motivasi lanjutan dan solusi untuk problem yang dialami para Muallaf. Pada tahap ini mereka akan diarahkan kepada orang yang paham tentang permasalahan yang dihadapi oleh Muallaf.

\section{Muallaf Center BKMR An-Nur dan Program Pembinaannya}

Muallaf Center BKMR An-Nur Provinsi Riau memberikan pembinaan terdiri dari materi tematik seperti akidah, syariah, fikih, belajar Iqro, dan diskusi umum. Pada saat tertentu juga mengundang ustaz dari luar untuk memberi pembinaan yang bertema umum. Secara umum pembinaan disebut sebagai sebuah perbaikan terhadap pola kehidupan yang direncanakan. Setiap manusia memiliki tujuan hidup tertentu dan ia memiliki keinginan untuk mewujudkan tujuan tersebut. Apabila tujuan hidup tersebut tidak tercapai maka manusia akan berusaha untuk menata ulang pola kehidupannya. Pembinaan juga dapat diartikan bantuan dari seseorang atau sekelompok orang yang ditujukan kepada orang atau sekelompok orang lain melalui materi pembinaan dengan tujuan dapat mengembangkan kemampuan, sehingga tercapai apa yang diharapkan. Selain itu, untuk melaksanakan kegiatan pembinaan diperlukan adanya perencanaan, pengorganisasian dan pengendalian (Tanzeh, 2008: 114).

Pembinaan dan bimbingan sangat perlu diberikan kepada para Muallaf, karena seorang Muallaf yang belum terbiasa dengan ibadah yang baru dan harus menjalani ibadah yang baru tersebut, mereka harus memiliki pengetahuan ilmu tentang Islam. Ketika mereka sudah memeluk agama Islam dan tidak mendapatkan pembinaan tentang ajaran Islam, banyak hal yang bisa dikhawatirkan antara lain, seorang Muallaf bisa sama sekali tidak bisa melakukan ibadah karena tidak ada yang membimbing.

Seorang Muallaf dapat melakukan pembinaan mandiri di tempat umum seperti belajar kepada guru ngaji, atau bagi Muallaf yang perempuan mengikuti perwiridan bersama ibukibuk di masjid. Akan tetapi ketika berkumpul dengan sesama Muallaf dan mengikuti pembinaan di Muallaf Center BKMR An-Nur Provinsi Riau, para Muallaf tidak hanya diberikan pembinaan seperti akidah, syariah, fikih, belajar Iqro, dan diskusi umum saja, tetapi juga akan mendapatkan pembinaan mental. Karena bagi seorang Muallaf, selain belajar tentang akidah, syariah, fikih, belajar Iqro, dan diskusi umum, mereka juga harus menguatkan hati mereka, agar niatnya untuk memilih agama Islam tetap istiqomah.

Pembinaan yang diberikan oleh Muallaf Center BKMR An-Nur Provinsi Riau adalah suatu kegiatan yang diperlukan oleh Muallaf untuk mengikat tali silaturahim dan juga untuk menambah ilmu pengetahuan tentang ajaran Islam. Kegiatan pembinaan terhadap para Muallaf dilakasanakan 4 (empat) kali dalam satu bulan setiap hari ahad (Minggu) dari pukul 
10.00-13.00 WIB, dan dibagi menjadi dua materi. Untuk yang memberikan materi akidah, syariah, dan fikih terdiri dari 1 ustaz pembina. Sedangkan untuk materi yang kedua yaitu pembinaan belajar Iqro dipimpin oleh 1 ustaz pembina.

\section{Simpulan}

Kehadiran Muallaf Center BKMR An-Nur Provinsi Riau dalam memberikan layanan pembinaan kepada Muallaf sangat penting. Di dalam tulisan ini saya telah menunjukkan bagaimana Muallaf Center sebagai lembaga keagamaan non-pemerintah berperan aktif melakukan pendampingan dan pembinaan kepada Muallaf. Muallaf Center BKMR An-Nur memberikan beberapa peran seperti peran fasilitator, administrator, konselor, motivator dan peran pembinaan kepada Muallaf. Melalui peran-peran ini mereka yang baru mengenal ataupun masuk ke dalam agama Islam (Muallaf) dapat terfasilitasi baik dari aspek spiritual atau pemahaman keagamaan Islam maupun aspek administrasi atau legalitas identitas keagamaan Muallaf. Temuan ini juga merefleksikan bahwa lembaga keagamaan nonpemerintah seperti Muallaf Center BKMR An-Nur memberikan kontribusi penting bagi dakwah Islam di Indonesia.

\section{Referensi}

Bungin, Burhan. (2003). Analisis Data Penelitian Kualitatif. Jakarta: PT Raja Grafindo Persada.

Coulson. (1996). Public Relations Pedoman Praktik Untuk Public Relations. Edisi Indonesia. Jakarta: PT. Gramedia Pustaka Utama.

Departemen Agama RI. (1998). Pedoman Pembinaan Muallaf. Jakarta: Departemen Agama RI.

Dokumentasi (Muallaf Center BKMR An-Nur Provinsi Riau).

Gunawan, Yusuf. (1992). Pengantar Bimbingan dan Konseling. Jakarta: PT. Gramedia Pustaka Utama.

Hakiki, Titian dan Rudi Cahyono. (2015). "Komitmen Beragama pada Muallaf (Studi Kasus pada Muallaf Usia Dewasa)," Jurnal Psikologi Klinis dan Kesehatan Mental, Vol. 4, No. 1 April, 20-28.

Hakim, Ramlah. (2013). "Pola Pembinaan Muallaf di Kabupaten Sidrap Provinsi Sulawesi Selatan," Jurnal Al-Qalam, Vol. 19, No.1 Juni, 85-96

King, Hary dan Sugiono. Metodologi Penelitian Administrasi. Bandung: Alfabeta.

Masduki, Toni Hartono, Vera Sardila, Dony Arung Triantoro. (2019). "Pemberdayaan Muslim Muallaf Melalui Home Industry Kerupuk Ikan Lomek di Desa Selat Akar," Jurnal Pemberdayaan Masyarakat: Media Pemikiran dan Dakwah Pembangunan, Vol. 3, No. 2, 425-450.

Pasolong, Harbani. (2013). Metodologi Penelitian Administrasi Publik. Bandung: Alfabeta.

Sabiq, Sayyid. (2009). Fiqhus Sunnah, Terj, Fiqih Sunnah. Jakarta: PT. Pena Pundi Aksara.

Sudarmo. (1990). Dasar-Dasar Motivasi Dalam Lingkungan Kerja. Jakarta: Ghalia Indonesia.

Tanzeh, Ahmad. (2008). Pengantar Metode Penelitian. Yogyakarta: Teras. 